equation increased $\mathrm{r}$ to $(0 \cdot 79$. Age added little more $(\mathrm{r}=0 \cdot 80)$.

\section{Discussion}

These data show a simple linear relation between height velocity and fasting serum insulin concentration. This association is probably indirect and secondary to changes in circulating growth hormone concentration. Growth in mid childhood is growth hormone dependent while that of puberty results from synergism between growth hormone and circulating sex steroids. ${ }^{25}$ High circulating concentrations of growth hormone are known to increase fasting insulin concentrations and to promote insulin resistance at peripheral tissues. ${ }^{\prime}$

The model proposed supports the observation of an increase in serum insulin concentrations associated with puberty. It suggests that a two to threefold rise in fasting serum insulin concentration occurs as a result of a change in growth velocity from pubertal values of about $5.5 \mathrm{~cm} /$ year to that seen during the pubertal growth spurt of $10 \mathrm{~cm} /$ year or more. These data may have importance for clinicians caring for pubertal diabetic patients. If the findings of this study were extrapolated as an index to total daily insulin requirement, such patients might need up to a threefold increase of insulin dosage to maintain euglycaemia and an acceptable growth spurt. As growth hormone secretion decreases after puberty it is possible that insulin requirements will also fall in adulthood.

\footnotetext{
References

I Pirart J. Diabetes mellitus and its degenerative complications: a propective study of $44(0)$ patients observed between 1947 and 1973. Diabetes Care 1978:1:168-88.252-63.

2 Hindmarsh P. Smith PJ. Brook CGD, Matthews DR. The relationship between height velocity and growth hormone secretion in short prepubertal children. Clin Endocrinol (Oxf) 1987:27:581-91.

Brook CGD. Growth assessment in childhood and adolescence. Oxford: Blackwell Scientific Publications, 1982

4 Morgan CR. Lazarow A. Immunoassay of insulin: two antibody system. Diabetes 1963:12:115-26.

Mauras N. Blizzard RM, Link K. Johnson ML. Rogol AD. Veldhuis JD. Augmentation of growth hormone secretion during puberty: evidence for a pulse amplitude-modulated phenomenon. J Clin Endocrinol Metab 1987:64:596-601.

6 Rosenfeld RG. Wilson DM. Dollar LA, Bennett A, Hintz RE. Both human pituitary growth hormone and recombinant DNA derived human growth hormone cause insulin resistance at a postreceptor sitc. J Clin Endocrinol Metab 1982:54:1033-8.
}

Correspondence to Dr CGD Brook. Endocrine Unit, Middlesex Hospital, Mortimer Street. London WIN 8AA

Accepted 20 January 1988

\title{
Prepubertal hypertrichosis: normal or abnormal?
}

\author{
J H BARTH, J D WILKINSON, * AND R P R DAWBER \\ Departments of Dermatology, Slade Hospital, Oxford, and "Wycombe General Hospital, High Wycombe
}

SUMMARY The pattern of hair growth, morphology of the hair shafts, and the hair root state are described in four girls and two boys with prepubertal hypertrichosis. The exact nosology of this form of excessive hair growth is discussed in relation to hirsuties and the possibility of it representing an 'atavistic' trait.

Hypertrichosis in childhood may be seen in a variety of congenital and metabolic disturbances, after administration of therapeutic agents in utero, and after birth and in association with chronic disease. ${ }^{1}$ In most of these disorders the excess hair growth is not considered to be a major component and is usually noted only for completion. In contrast, most cases of hypertrichosis lanuginosa have been re- ported because the excess hair growth is the primary disorder.

We report a series of children with hypertrichosis as this pattern appears to have been ignored or, conversely, given the diagnostic label of hirsuties: the latter is a diagnosis that suggests an aetiology of androgen hormone excess.

\section{Case reports}

Six children with noticeable congenital generalised hypertrichosis were seen. There were two boys (ages $31 / 2$ and $71 / 4$ ) and four girls (ages $23 / 4,6,61 / 2$, and 8 ). Two boys and one girl were Asian; one of the other three girls had a Celtic father, the other parents were Anglo Saxon. Five of the children had dark hair and only one had blonde hair. Five of the children had no family history of excess hair. One of 
the girls had a brother with 'hairy elbows.' All the children had normal physical and mental development and were entirely healthy. None of the children had been exposed to drugs known to cause hypertrichosis either in the prenatal or postnatal periods. Only the four girls presented with the problem of excess hair; one of the boys was seen when he attended a dermatology clinic with his brother, the other was coincidentally seen with insect bites.

\section{PATTERN OF HAIR GROWTH}

The pattern of hair growth was similar in all cases, although there were varying degrees of severity. In the two boys, there were sparse fine pigmented hairs around the root of the penis but this was not progressive. In none of the other cases was there any suggestion of axillary or pubic hair development. The external genitalia were normal and appropriate for the age of the children and there was no breast development in the girls. The pattern of hair growth was as follows:

\section{Face}

There was a dense growth of terminal hair over the scalps, which had a low anterior hair line. This was

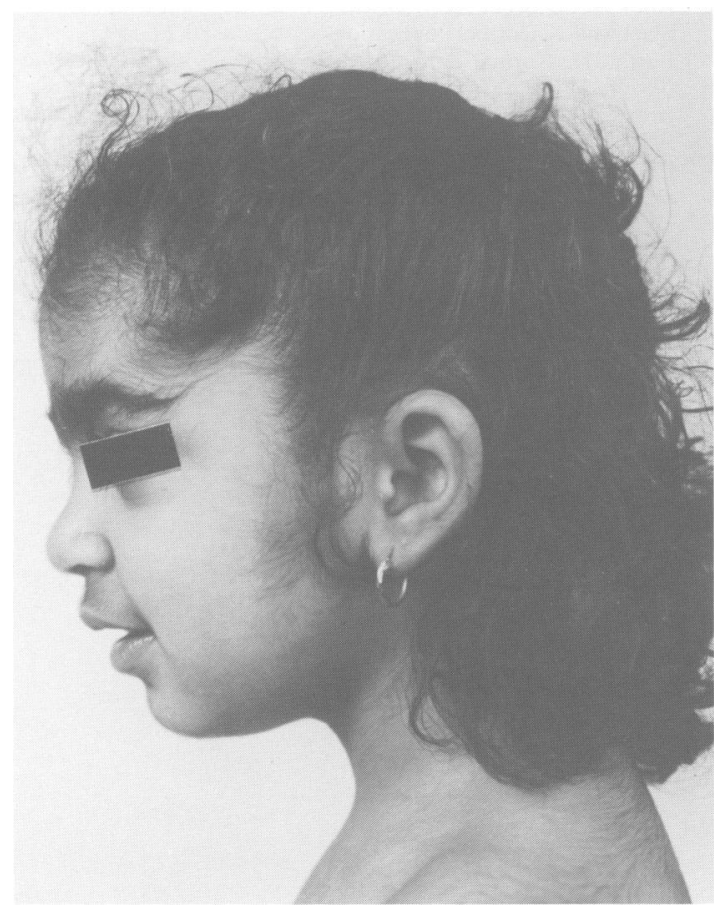

Fig 1 Lateral view of the face and shoulder of the Asian girl showing bushy eyebrows and hypertrichosis on the forehead, side of the face, ear, and shoulder. particularly noticeable in the temporal regions where the scalp hair merged into bushy eyebrows. The faces were covered with fine but densely pigmented hair (fig 1).

\section{Trunk}

The hair was more pronounced over the back and there was only minimal growth on the front of the chest and abdomen. The hair streams flowed around the sides of the chest to the back, met in the midline and continued towards the sacrum, and gave an appearance of an inverted fir tree. In three of the children a whorl was present overlying the spine between the scapulae (fig 2).

\section{Limbs}

The arms and legs were covered with long hair shafts which had the nature of thick, coarse, and curly terminal hair; these differed from other sites which were covered with vellus hair. This was appreciable on the legs and at the elbow region where the hair growth was profuse.

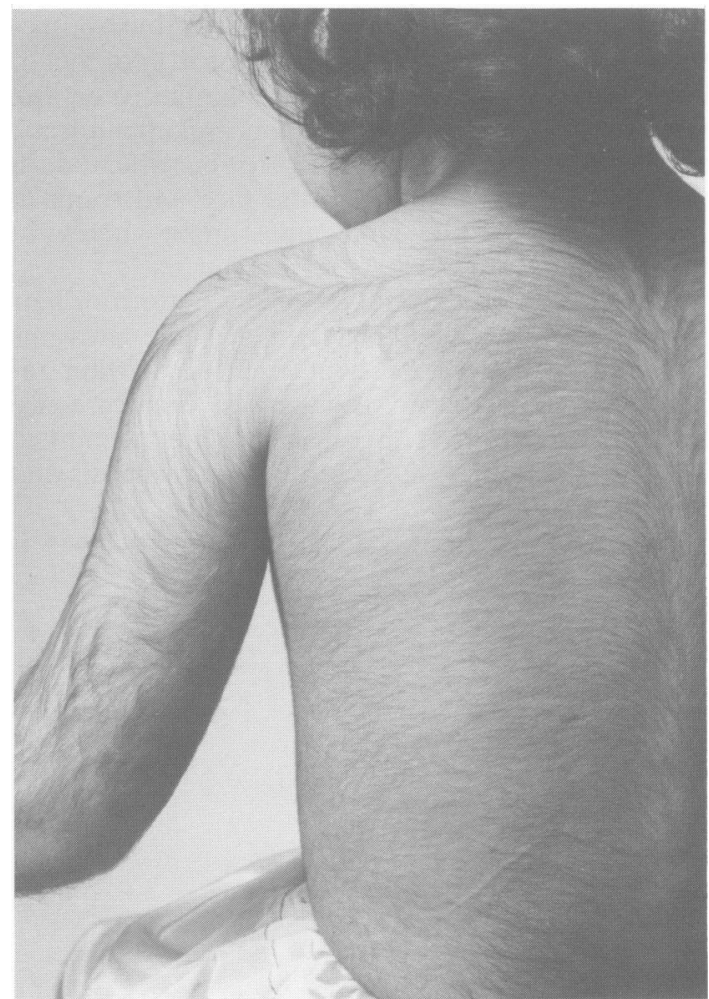

Fig 2 Later view of the trunk of the Asian girl showing hypertrichosis of the back and shoulder, and dense growth on the arm particularly around the elbow. 
EXAMINATION OF HAIR

Hairs plucked from the upper back and either thigh or elbow region were examined by light microscopy. In all cases, the hair shafts had normal morphology with well formed medullas. Examination of the hair roots showed both anagen and telogen bulbs from all sites: unfortunately, many hairs had fractured above the roots preventing an accurate assessment of the ratio of anagen to telogen bulbs.

\section{Discussion}

The pattern of hair growth in these otherwise healthy children is quite unlike that seen in hirsuties. Hirsuties is the pattern seen in adults with cutaneous or systemic virilism; it is only seen in children suffering from virilising disorders-for example, congenital adrenal hyperplasia or hormone secreting tumours. In hirsuties the hair growth is predominantly on the upper lip, chin, abdomen, and inner thighs.

The main difference between the hypertrichotic pattern described in this report and hirsuties was the hair growth on the face and trunk. The described facial hair pattern was dominated by bushy eyebrows, a low frontal hairline, and a hairy forehead. The hair on the trunk was predominantly on the back and extended to the shoulders and upper arms: both these sites are the last to be affected in hirsuties. The hair shafts on the face and trunk in hypertrichosis are fine, silky, and straight whereas in hirsuties they are thick, coarse, and curly. ${ }^{2}$

Such a detailed description of the pattern of hair growth has only been given in a single previous report of uncomplicated hypertrichosis. ${ }^{3}$ Other reports in the paediatric and genetic literature are difficult to interpret because of the seemingly interchangeable use of the terms hypertrichosis and hirsuties.

The aetiology of this form of hypertrichosis is

obscure. It has been suggested that body hair is an 'atavistic relic'. ${ }^{4}$ This concept, however, is not supported by detailed observations of hair patterns in many species of animals, including primates, all of whom have completely different patterns, ${ }^{5}$ the most prominent being the direction of hair growth on the back. In animals the hair grows from the midline towards the belly so that, in a quadruped, the hair acts as a watershed; in hypertrichotic children the direction is reversed.

It is often held that 'racial hirsuties,' which is probably identical to the hypertrichosis described above, is common among Asians. ${ }^{1}$ It is clear from this report, however, that hypertrichosis does occur in white children, although it may appear to be more prevalent among Asian children as their dark hair is more noticeable. The relative absence of body hair in the Mongoloid races further confirms that racial differences do occur. ${ }^{6}$

It is unknown if the pattern of hypertrichosis described represents an abnormal entity or whether it occurs as an extreme form of the normal range of hair growth. Larger population studies of children will be required to determine this issue.

\section{References}

1 Rook AJ. Dawber RPR. Diseases of the hair and scalp. Oxford: Blackwell Scientific Publications, 1982:78-80,233-59.

2 Barth JH. Normal hair growth in children. Pediatr Dermatol 1987;4:173-84.

3 Broster LR. Hypertrichosis: a report of three cases. $\mathrm{Br}$ Med J 1950;i:1171-4.

4 Eckes LK. Korperbehaarung: ein atavistisches relikt? Der Hautarzt 1987:38:125-30.

5 Kidd W. The direction of hair in amimals and man. London: Adam and Charles Black, 1903.

${ }^{6}$ Eckes LK. Bemerkungen zur ethnischen variation des kopfhaares. Der Hautarzt 1985;36:381-5.

Correspondence to Dr J H Barth, Department of Dermatology, Slade Hospital, Headington, Oxford OX3 7JH.

Accepted 8 February 1988 